\section{References}

1. Walsh MP, Seto J, Jones MS, Chodosh J, Xu W, Seto D. Computational analysis identifies human adenovirus type 55 as a re-emergent acute respiratory disease pathogen. J Clin Microbiol. 2010;48:991-3. http://dx.doi.org/10.1128/JCM.01694-09

2. Kajon AE, Dickson LM, Metzgar D, Houng HS, Lee V, Tan BH. Outbreak of febrile respiratory illness associated with adenovirus 11a infection in a Singapore military training camp. J Clin Microbiol. 2010;48:1438-41. http://dx.doi.org/10.1128/ JCM.01928-09

3. Cao B, Huang GH, Pu ZH, Qu JX, Yu XM, Zhu Z, et al. Emergence of community-acquired adenovirus type 55 as a cause of community-onset pneumonia. Chest. 2014;145:79-86. http://dx.doi.org/10.1378/chest.13-1186

4. Salama M, Amitai Z, Amir N, Gottesman-Yekutieli T, Sherbany H, Drori Y, et al. Outbreak of adenovirus type 55 infection in Israel. J Clin Virol. 2016;78:31-5. http://dx.doi.org/ 10.1016/j.jcv.2016.03.002

5. Lafolie J, Mirand A, Salmona M, Lautrette A, Archimbaud C, Brebion A, et al. Severe pneumonia associated with adenovirus type 55 infection, France, 2014. Emerg Infect Dis. 2016;22:2012-4. http://dx.doi.org/10.3201/eid2211.160728

6. Heo JY, Noh JY, Jeong HW, Choe KW, Song JY, Kim WJ, et al. Molecular epidemiology of human adenovirus-associated febrile respiratory illness in soldiers, South Korea. Emerg Infect Dis. 2018;24:1221-7. http://dx.doi.org/10.3201/eid2407.171222

7. Zhu Z, Zhang Y, Xu S, Yu P, Tian X, Wang L, et al. Outbreak of acute respiratory disease in China caused by B2 species of adenovirus type 11. J Clin Microbiol. 2009;47:697-703. http://dx.doi.org/10.1128/JCM.01769-08

8. Carr MJ, Kajon AE, Lu X, Dunford L, O'Reilly P, Holder P, et al. Deaths associated with human adenovirus-14p1 infections, Europe, 2009-2010. Emerg Infect Dis. 2011;17:1402-8. http://dx.doi.org/ $10.3201 / 1708.101760$

9. Huang G, Yu D, Zhu Z, Zhao H, Wang P, Gray GC, et al. Outbreak of febrile respiratory illness associated with human adenovirus type $14 \mathrm{p} 1$ in Gansu Province, China. Influenza Other Respi Viruses. 2013;7:1048-54. http://dx.doi.org/10.1111/irv.12118

10. Centers for Disease Control and Prevention. Acute respiratory disease associated with adenovirus serotype 14 - four states, 2006-2007. MMWR Morb Mortal Wkly Rep. 2007; $56: 1181-4$

Address for correspondence: Qiwei Zhang, Southern Medical University, School of Public Health, 1838 N Guangzhou Ave, Guangzhou, Guangdong 510515, China; email: zhangqw@smu.edu.cn.

\title{
Worldwide Reduction in MERS Cases and Deaths since 2016
}

\section{Christl A. Donnelly, Mamun R. Malik, Amgad Elkholy, Simon Cauchemez, Maria D. Van Kerkhove}

Author affiliations: University of Oxford, Oxford, UK (C.A. Donnelly); Imperial College London, London, UK (C.A. Donnelly); World Health Organization Regional Office for the Eastern Mediterranean, Cairo, Egypt (M.R. Malik, A. Elkholy); Institut Pasteur, Paris, France (S. Cauchemez); World Health Organization, Geneva, Switzerland (M.D. Van Kerkhove)

DOI: https://doi.org/10.3201/eid2509.190143

Since 2012, Middle East respiratory syndrome (MERS) coronavirus has infected 2,442 persons worldwide. Case-based data analysis suggests that since 2016, as many as 1,465 cases and 293-520 deaths might have been averted. Efforts to reduce the global MERS threat are working, but countries must maintain vigilance to prevent further infections.

Grom 2012 through May 31, 2019, Middle East respiratory syndrome coronavirus (MERS-CoV) has infected 2,442 persons and killed 842 worldwide (1). MERS-CoV is currently circulating in dromedary camels in Africa, the Middle East, and southern Asia; however, most cases of human infection have been reported in the Arabian Peninsula (2). Large hospital outbreaks in 2014 and 2015 $(3,4)$ (Appendix Figure 1, https://wwwnc.cdc.gov/EID/ article/25/9/19-0143-F1.htm) motivated affected countries to substantially invest in prevention and control activities.

To estimate the potential number of MERS cases and deaths that might have been averted since 2016 had the risk levels of 2014-2015 continued, we analyzed case-based data on laboratory-confirmed human cases of MERS-CoV infections reported to the World Health Organization (5). We categorized cases as either secondary (human-to-human transmission) or community-acquired (presumed camel-tohuman transmission). In addition, we used case-based data on date of onset (for symptomatic infections) or report (for asymptomatic infections), outcome (died/recovered), and dates and sizes of reported clusters of human-to-humantransmission cases $(3,4,6-8)$.

We compared incidence of camel-to-human-transmission cases (i.e., community-acquired cases, assuming all of those not positively attributed to human-to-human transmission were in this category) during 2016, 2017, and 2018 (through September only) with incidence during 2014 2015, assuming that case numbers were Poisson distributed 
(yielding a 2-sided $\mathrm{p}$ value). Furthermore, we obtained the expected total number of cases in 2016, 2017, and through September 2018, conditional on the incidence of community-acquired cases, by simulating 10,000 times from the distribution of human-to-human-transmission cluster sizes observed during 2014-2015. Thus, the observed incidence rates in these years could be compared with simulations to test the null hypothesis that human-to-human transmission levels remained constant since 2014-2015 (yielding a 2 -sided $p$ value). The intervals reported are the 2.5 th and 97.5th percentiles of the simulations ( $95 \%$ CIs). We examined a range of mortality rates from healthcare-associated outbreaks in South Korea and Saudi Arabia $(3,5)$ and the case-fatality ratio (CFR) from all reported cases globally (35.5\%, 800 fatalities/2,254 cases) (9). When numbers of cases averted were not statistically significant, we truncated the lower bound of the $95 \%$ CI to 0 cases averted.

Of the 2,254 laboratory-confirmed cases reported to the World Health Organization from 2012 through October 1, 2018 (Appendix Figure 1), 1,087 were classified as humanto-human transmssion cases and the remaining 1,167 as community-acquired cases. During this same period, clusters/outbreaks were reported each year (range 2-255 cases).

Although 739 cases were reported in 2014 and 768 cases in 2015, only 244 cases were reported in 2016, another 244 in 2017, and 113 through September 2018. We assessed potential components of this reduction (i.e., reduction of community-acquired cases, human-to-human transmission cases, or both). The incidence of community-acquired cases was 177 in 2016, 151 in 2017, and 86 through September 2018 (Appendix Table). These rates were each significantly $(p<0.001)$ lower than expected compared with the incidence in 2014-2015 (334 for 2016, 334 for 2017, and 251 through September 2018). Conditional on the number of community-acquired cases, we observed no significant reduction in the risk for secondary cases from 2014-2015 to 2016, 2017, and through September 2018, although we did find nonsignificant trends. We estimated that 154 secondary cases $(95 \%$ CI $0-495)$ were averted from the 177 community-acquired cases in 2016,
96 (95\% CI 0-419) from the 151 community-acquired cases in 2017, and 80 (95\% CI 0-338) from the 86 community-acquired cases through September 2018, totaling 330 (95\% CI 0-819) from the 414 community-acquired cases during 2016-September 2018 (Table). Assuming a $20 \%$ CFR $(3,10)$, these 330 (95\% CI 0-819) cases averted correspond to 66 (95\% CI 0-164) expected deaths averted; assuming a $35.5 \%$ CFR (9), they correspond to $117(95 \%$ CI 0-291) expected deaths averted.

The total number of cases averted, when simultaneously taking into account reduced camel-to-human and human-to-human transmission, was estimated at 507 (95\% CI 189-967) in 2016, 507 (95\% CI 189-967) in 2017, and 451 (95\% CI 191-855) through September 2018, totaling $1,465(95 \%$ CI $895-2,165)$ cases averted and 293 (95\% CI 179-433) expected deaths averted (under the assumption of a 20\% CFR) from 2016 through September 2018. Assuming a $35.5 \%$ CFR, this estimate corresponds to $520(95 \%$ CI 318-769) expected deaths averted.

We believe that affected countries are reducing the global threat of MERS by addressing knowledge gaps with regard to transmission, enhancing surveillance, and strengthening the ability to detect cases early and contain outbreaks through improved infection prevention and control measures in hospitals. Critical for preventing international spread and sustained transmission have been improved prevention and control measures in hospitals, restriction of camel movement in affected areas, stronger and more comprehensive investigations of cases and clusters, and improved communication.

Although global efforts seem to have prevented hundreds of infections and deaths, vigilance must be maintained by all countries. More needs to be done to limit spillover infections from dromedaries, which requires stronger surveillance of dromedary populations and persons in direct contact with infected herds and accelerated development of a vaccine for dromedaries (2). The international community and affected countries have a collective and shared responsibility to curtail a major health security threat such as MERS in the Middle East and beyond.

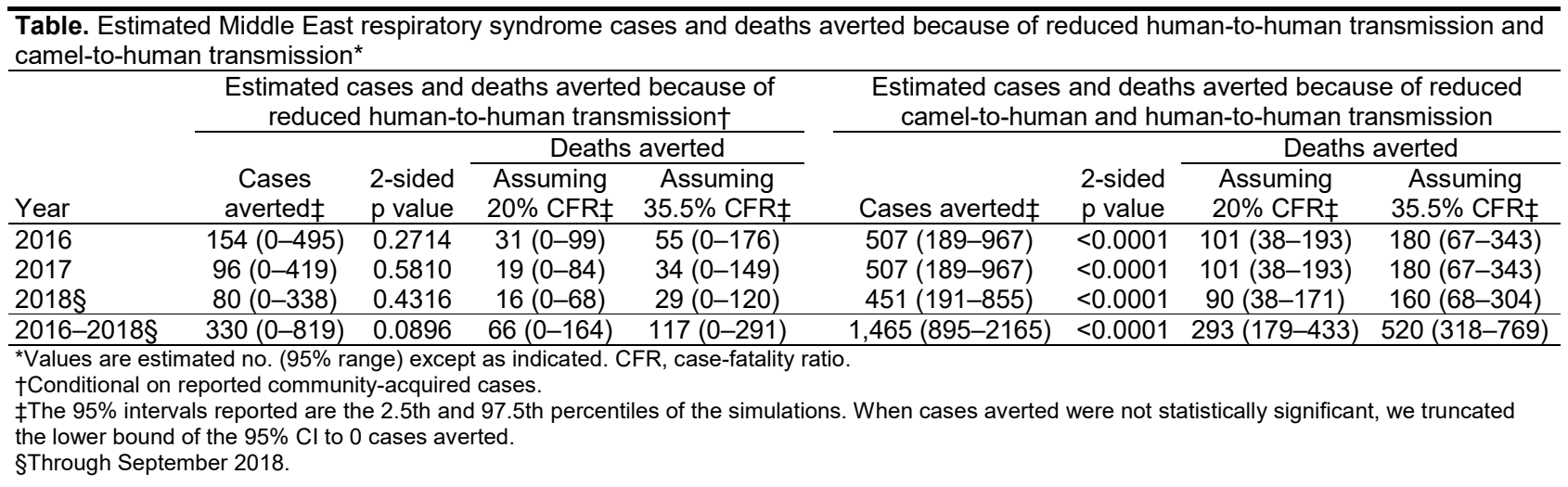




\section{Acknowledgments}

We thank the many ministry and government officials working to detect and respond to MERS cases and clusters.

C.A.D. thanks the UK Medical Research Council for center funding (MR/R015600/1) and the National Institute for Health Research for funding the NIHR Health Protection Research Unit in Modelling Methodology and the Vaccine Efficacy Evaluation for Priority Emerging Diseases Epidemic Modelling Consortium (EPIDZO34). S.C. acknowledges financial support from the Investissement d'Avenir program, the Laboratoire d'Excellence Integrative Biology of Emerging Infectious Diseases program (grant ANR-10LABX-62-IBEID), the Models of Infectious Disease Agent Study of the National Institute of General Medical Sciences, and the AXA Research Fund.

\section{About the Author}

Dr. Donnelly is a professor of applied statistics at the University of Oxford and a professor of statistical epidemiology at Imperial College London. As a statistician and epidemiologist, her research interest is the spread and control of infectious diseases, with a particular focus on outbreaks.

\section{References}

1. World Health Organization. Middle East respiratory syndrome coronavirus (MERS-CoV) [cited 2019 June 4]. http://www.who.int/ emergencies/mers-cov

2. FAO-OIE-WHO MERS Technical Working Group. MERS: progress on the global response, remaining challenges and the way forward. Antiviral Res. 2018;159:35-44. https://doi.org/10.1016/ j.antiviral.2018.09.002

3. Ki M. 2015 MERS outbreak in Korea: hospital-to-hospital transmission. Epidemiol Health. 2015;37:e2015033. https://doi.org/10.4178/epih/e2015033

4. Oboho IK, Tomczyk SM, Al-Asmari AM, Banjar AA, Al-Mugti H, Aloraini MS, et al. 2014 MERS-CoV outbreak in Jeddah-a link to health care facilities. N Engl J Med. 2015;372:846-54. https://doi.org/10.1056/NEJMoa1408636

5. World Health Organization. 2017 Middle East respiratory syndrome coronavirus: case definition for reporting to WHO [cited 2019 Jun 4]. https://www.who.int/csr/disease/coronavirus_ infections/case_definition

6. Balkhy HH, Alenazi TH, Alshamrani MM, Baffoe-Bonnie H, Al-Abdely HM, El-Saed A, et al. Notes from the field: nosocomial outbreak of Middle East respiratory syndrome in a large tertiary care hospital-Riyadh, Saudi Arabia, 2015. MMWR Morb Mortal Wkly Rep. 2016;65:163-4. https://doi.org/10.15585/ mmwr.mm6506a5

7. Assiri A, McGeer A, Perl TM, Price CS, Al Rabeeah AA, Cummings DA, et al.; KSA MERS-CoV Investigation Team. Hospital outbreak of Middle East respiratory syndrome coronavirus. N Engl J Med. 2013;369:407-16. https://doi.org/10.1056/ NEJMoa1306742

8. Bernard-Stoecklin S, Nikolay B, Assiri A, Aziz Bin Saeed AA, Karim Ben Embarek P, El Bushra H, et al. Comparative analysis of eleven healthcare-associated outbreaks of MERS-CoV from 2015-2017. Sci Rep. 2019;9:7385. https://doi.org/10.1038/ s41598-019-43586-9
9. World Health Organization. Middle East respiratory syndrome coronavirus (MERS-CoV) [cited 2019 Jun 4]. http://www.who.int/ emergencies/mers-cov

10. World Health Organization. Middle East respiratory syndrome coronavirus (MERS-CoV) infection-Republic of Korea [cited 2019 Jun 4]. http://www.who.int/csr/don/12-september-2018mers-republic-of-korea

Address for correspondence: Maria D. Van Kerkhove, World Health Organization, High Threat Pathogens, Global Infectious Hazards Management, Health Emergencies Program, Geneva, Switzerland; email: vankerkhovem@who.int

\section{Limited Scope of Shorter Drug Regimen for MDR TB Caused by High Resistance to Fluoroquinolone}

\author{
Pravin K. Singh, Amita Jain \\ Author affiliation: King George Medical University, Lucknow, India
}

DOI: https://doi.org/10.3201/eid2509.190105

Resistance to second-line tuberculosis drugs for patients with multidrug-resistant tuberculosis has emerged globally and is a potential risk factor for unfavorable outcomes of shorter duration drug regimens. We assessed the proportion of patients eligible for a shorter drug regimen in Uttar Pradesh, India, which had the highest rate of multidrug-resistant tuberculosis in India.

$\mathrm{I}^{\mathrm{n}}$ ndia has the largest burden of multidrug-resistant (MDR) tuberculosis (TB) worldwide (1). The success rate for MDR TB treatment is low (47\%), largely caused by death, suboptimal adherence of patients to long treatment courses, and frequent drug-related adverse events (2).

In 2016, the World Health Organization recommended a shorter drug regimen (9-12 months) for patients with MDR TB or rifampin-resistant TB who had not received second-line drugs (SLDs) and in whom resistance to fluoroquinolones and injectable SLDs is considered highly unlikely (3). A shorter regimen is a promising step toward high treatment success rates. Recently, this regimen was instituted in Uttar Pradesh, which has $\approx 20 \%$ of the total 